\title{
Retrospective Analysis of Patients admitted to Emergency Dental Clinic of a Secondary Care Public Hospital in Turkey
}

\author{
${ }^{1}$ Onur Agmaz, ${ }^{2}$ Yahya A Acar, ${ }^{3}$ Erdem Cevik, ${ }^{4} \mathrm{Cem}$ Uyguner, ${ }^{5}$ Baris E Oral, ${ }^{6}$ Cenkhan Bal
}

\begin{abstract}
Background: This study aims to evaluate dental emergency visits in a public hospital as the number of dental emergency visits has recently increased.
\end{abstract}

Materials and methods: This was a retrospective observational study. This study was approved by the local ethical committee and data were recorded from the dental emergency service record book between January 1, 2012, and December 31, 2013

Results: In total, 1,477 (4.01\%) patients were admitted to emergency dentist services. Mean age was $24.59 \pm 11.07$ (minmax: 2-76) and 978 (66.2\%) patients were between 19 and 35 years old. The most common diagnosis was pulpitis or periapical abscess $(n=1033,69.9 \%)$ and the most common practice was the prescription of antibiotics and/or analgesics ( $n=885,59.9 \%)$.

Conclusion: The latest increase in the number of dental emergency visits is a burden, and emergency physicians must be capable of differentiating the real emergencies from common uncomplicated complaints.

Keywords: Dental health services, Epidemiology, Hospital emergency services.

How to cite this article: Agmaz O, Acar YA, Cevik E, Uyguner C, Oral BE, Bal C. Retrospective Analysis of Patients admitted to Emergency Dental Clinic of a Secondary Care Public Hospital in Turkey. Int J Experiment Dent Sci 2017;6(1):14-16.

Source of support: Nil

Conflict of interest: None

\footnotetext{
${ }^{1}$ Research Associate, ${ }^{2}$ Physician, ${ }^{3}$ Associate Professor ${ }^{4-6}$ Private Practioner

${ }^{1}$ Department of Dentistry, Kars Dentistry Hospital, Kars, Dogu Anadolu, Turkey

${ }^{2}$ Department of Emergency Medicine, Etimesgut Military Hospital, Ankara, Ic Anadolu, Turkey

${ }^{3}$ Department of Emergency Medicine, Van Military Hospital, Van Dogu Anadolu, Turkey

${ }^{4}$ Medical Center, Air Transport Main Base, Ankara, Ic Anadolu Turkey

${ }^{5,6}$ Department of Dentistry, Etimesgut Military Hospital, Ankara Ic Anadolu, Turkey

Corresponding Author: Onur Agmaz, Research Associate Department of Dentistry, Kars Dentistry Hospital, Kars, Dogu Anadolu, Turkey, Phone: +905458598599, e-mail: oagmaz@ hotmail.com.tr
}

\section{INTRODUCTION}

Emergency visits due to various dental conditions are frequent. ${ }^{1,2}$ Dental complaints are problematic for emergency physicians (EPs), and it was reported that only $67 \%$ are managed appropriately. ${ }^{3}$ Few emergency departments (EDs) have dentists and this makes it necessary for EPs to evaluate these patients. The aim of this study is to evaluate emergency visits due to dental problems.

\section{MATERIALS AND METHODS}

This is a retrospective observational study of emergency dental visits of a secondary care public hospital where 20,000 patients are admitted annually. Local ethical committee approved the study protocol.

\section{Data Collection}

The emergency dentist works in the research center after office hours. The dentist has a separate room and register book. Patient data were collected from medical records through this register book between January 1 , 2012, and December 31, 2013. The study form included the demographic features of patients, final diagnosis, the tooth number causing problem, and applied treatments in the ED.

\section{Statistical Analysis}

Descriptive statistics are presented as frequency and percentage for categorical variables, whereas continuous data are presented as mean \pm standard deviation for normally distributed data. Statistical Package for the Social Sciences, version 15.0 (SPPS Inc., Chicago, Illinois, USA) was used.

\section{RESULTS}

A total of 36,875 patients were admitted to the ED during the study, and 1477 (4.01\%) were dental visits. In the study, $331(22 \%)$ of patients were females and mean age of the subjects was $24.59 \pm 11.07$ (min-max: 2-76); 978 (66.2\%) patients were between 19 and 35 years old (Table 1). The most common diagnosis was pulpitis or periapical abscess $(n=1,033,69.9 \%)$ and the most common practice 
Retrospective Analysis of Patients admitted to Emergency Dental Clinic of a Secondary Care Public Hospital in Turkey

Table 1: Age groups of patients

\begin{tabular}{lll}
\hline Age group (years) & $n$ & $\%$ \\
\hline $0-6$ & 46 & 3.1 \\
$7-18$ & 216 & 14.6 \\
$19-35$ & 978 & 66.2 \\
$36-50$ & 194 & 13.1 \\
$>51$ & 43 & 3.0 \\
\hline
\end{tabular}

Table 3: Treatments given in the dental emergency service

\begin{tabular}{lll}
\hline Applied procedure & $n$ & $\%$ \\
\hline None & 75 & 5.1 \\
Prescription of analgesics and/or antibiotics & 885 & 59.9 \\
Intramuscular injection of analgesics, & 230 & 15.6 \\
antibiotics, or local anesthesia & & \\
Minor oral surgical procedures & 139 & 9.4 \\
Endodontic and restorative procedures & 63 & 4.3 \\
Prosthodontic procedures & 36 & 2.4 \\
Consultation & 8 & 0.5 \\
Other & 41 & 2.8 \\
\hline
\end{tabular}

was the prescription of antibiotics and/or analgesics ( $\mathrm{n}=885,59.9 \%$ ) (Table 2). The second most frequently used treatment was intramuscular injection of analgesics, antibiotics, or local anesthetics $(n=230,15.6 \%)$, while the third one was minor oral surgical procedures (139, 9.4\%) (Table 3). Only 8 patients were traumatic and only 12 patients were consulted or referred to other clinics for several reasons. First molars constituted the largest group [16 ( $\mathrm{n}=107,7.2 \%) ; 26(102,6.9 \%) ; 36(\mathrm{n}=154,10.4 \%)$; $46(\mathrm{n}=147,10.0 \%)]$ among patients.

\section{DISCUSSION}

Emergency department visits in the United States have been increasing in the last decade. ${ }^{1,4}$ It was reported that dental emergency visits accounted for 0.91 to $1.7 \%$ of all $\mathrm{ED}$ visits, a $\$ 2.7$ billion cost for a 3-year period. ${ }^{4-6}$ Additionally, pediatric emergency dental visits doubled between 1982 and 1991. ${ }^{7}$ In epidemiologic studies from Turkey, Söyüncü et $\mathrm{l}^{8}$ reported that dental emergency visits account for $3 \%$ of all ED visits. In our population, dental emergency visits accounted for $4.01 \%$ of all emergency visits and that was compatible with the current literature.

It was reported that among 798,000 annual visits to ED with dental problems, 19- to 35-year-old age group was the highest (accounted for $50.6 \%$ of all dental ED visits) in the United States, and children under 7 years constituted the smallest portion of ED visits. ${ }^{2,4,6}$ That was similar in Turkish population and $38.3 \%$ of dental emergency visits were in the 16 - to 25 -year-old age group, and $5.4 \%$ of all dental emergency visits were pediatric patients. ${ }^{8,9}$ Our study showed similar results, and most of the patients $(66.2 \%)$ were young adults aged 19 to 35 years and 3.1\% of them were pediatric patients.
Table 2: Diagnosis of the patients who visited dental emergency service

\begin{tabular}{lll}
\hline Diagnosis & $n$ & $\%$ \\
\hline None & 2 & 0.1 \\
Dental problem, not otherwise specified & 167 & 11.3 \\
Pulpitis or periapical abscess & 1033 & 69.9 \\
Pericoronitis, alveolitis & 102 & 6.9 \\
Broken tooth or trauma effect on other tissues & 31 & 2.1 \\
Gingivitis, periodontitis & 103 & 7.0 \\
Teething and eruption & 39 & 2.6 \\
\hline
\end{tabular}

The rate of patients who never visited a dentist was reported as $9.9 \%$ and who never brushed teeth was reported as $7.6 \%$ for the 35 to 44 years age group and periodontal healthy individuals were just $15.7 \%{ }^{10}$ According to a research that was conducted in 2004, regular dental visit rate was reported as $1.1 \%$ and dental visit just in case of complaint was reported to be $88.2 \% .{ }^{10}$ These data might suggest that adults do not care about their oral health properly, which causes dental problems and a rise in emergency visits. In other words, tooth care awareness has not reached the desired level.

Toothache has been reported as the most frequent complaint in emergency dental visits in adult and pediatric population. ${ }^{6,9}$ The most common diagnoses reported in the current literature were dental/periapical abscess (14.8-62.7\%), crown/root carries (20.4-95.9\%), and trauma (1.7-8.7\%). ${ }^{2,4,6,8,10}$ However, differences in the classification of current studies make it difficult to assess diagnosis definitely. According to our results, the most common diagnosis was pulpitis or periapical abscess $(69.9 \%)$, which was similar to the literature.

Current literature reported that in most of the dental emergency visits (32.7-80\%), analgesics and antibiotics were prescribed. ${ }^{2,8}$ Hospitalization rate of emergency dental visits was reported between 1 and 9\%. ${ }^{2,6}$ Our results similarly showed that the most common practice was analgesic and antibiotic prescription (59.9\%). However, there are no clear data about hospitalization, only 12 patients were referred or consulted to other clinics. This data might show that dental pain is the main reason for dental emergency visits, and dentists are focused solely on pain rather than solving the fundamental problem and providing a permanent treatment.

Being self-paid and Medicaid coverage were reported to be the factors affecting the increase in dental emergency visits. ${ }^{4}$ The EDs are particularly important when it comes to dental problems of people who lack private insurance. ${ }^{2}$ Increased ED use is a health care coverage system problem, which makes it difficult to access regular medical care. Neely et $\mathrm{al}^{11}$ reported that the reduced number of people with health insurance is associated with increased emergency dental visits as much as $14 \%$. 
It was also reported that $30.2 \%$ of patients admitted to dental emergency services had no insurance, and 21.5\% were on Medicaid. ${ }^{7}$ Luzzi and Spencer ${ }^{12}$ reported that patients prefer emergency dental service because of the lack of access to general care services. Cohen et $\mathrm{al}^{13}$ reported that severe pain (78.6\%), no insurance/no money $(9.8 \%)$, and not being able to get an appointment $(7.6 \%)$ were the most common reasons for contacting ED rather than a dentist. Insurance coverage is a global problem in health care systems and might increase the number of dental emergency visits. However, in Turkey, almost all the population is under public health coverage system and dental clinic visits are also under coverage. Increase in the dental emergency visits can be attributed to the lack of time and oral health awareness.

Emergency physicians are usually not sufficiently trained for dental cases, and routine dental care is unavailable in most EDs, and patients are usually unaware of this. ${ }^{14}$ Red flags among dental emergencies are trismus, fever, unstable vital signs, pain out of proportion to physical findings, difficulty in breathing, inability to swallow secretions, elevation of the floor of the mouth, neck swelling, deviation of the uvula and/or trachea, bulging of the lateral pharyngeal wall, deterioration of a patient who has been taking antibiotics, and lastly immune system compromise. ${ }^{15}$ But these complaints were not seen in dental emergency visits and they are mostly uncomplicated dental pain. It was reported that uncomplicated dental pain visits and opioid prescription can be reduced by applying guidelines and educating both patients and physicians. ${ }^{14,16}$ We also concluded that effective governmental and hospital policies may have positive effects on the evaluation of dental EPs (e.g., reducing frequency of total visits, rate of opioid prescription, etc.)

\section{LIMITATIONS}

Because of the retrospective design of this study, we could not reach the data on whether patients seek definitive care after ED visit.

\section{CONCLUSION}

Admission rates to EDs for a dental problem are increasing, and nontraumatic dental complaints are seen more frequently than expected in EDs. This has various causes but considering that many EDs do not have a dental clinic, EPs should be capable of diagnosing real dental emergencies. They should be aware that dental emergency visits are increasing and institutional policies must be based on the most frequent causes, simple treatment, and follow-up modalities of dental emergency visits.

\section{REFERENCES}

1. Tang N, Stein J, Hsia RY, Maselli JH, Gonzales R. Trends and characteristics of US emergency department visits, 1997-2007. JAMA 2010 Aug;304(6):664-670.

2. Lewis C, Lynch H, Johnston B. Dental complaints in emergency departments: a national perspective. Ann Emerg Med 2003 Jul;42(1):93-99.

3. Nalliah RP, Allareddy V, Allareddy V. Dentists in the US should be integrated into the hospital team. Br Dent J 2014 Apr;216(7):391-392.

4. Hong L, Ahmed A, McCunniff M, Liu Y, Cai J, Hoff G. Secular trends in hospital emergency department visits for dental care in Kansas City, Missouri, 2001-2006. Public Health Rep 2011 Mar-Apr;126(2):210-219.

5. Allareddy V, Rampa S, Lee MK, Allareddy V, Nalliah RP. Hospital-based emergency department visits involving dental conditions: profile and predictors of poor outcomes and resource utilization. J Am Dent Assoc 2014 Apr;145(4):331-337.

6. Verma S, Chambers I. Dental emergencies presenting to a general hospital emergency department in Hobart, Australia. Aust Dent J 2014 Sep;59(3):329-333.

7. Zeng Y, Sheller B, Milgrom P. Epidemiology of dental emergency visits to an urban children's hospital. Pediatr Dent 1994 Nov-Dec;16(6):419-423.

8. Söyüncü S, Oktay C, Ertan C, Eken C, Janitzky A. Evaluation of patients who admit to emergency department with dental and gingival problems. Turk J Emerg Med 2005;5(2):65-68.

9. Odabas M, Deveci C, Alacam A. Retrospective analysis of treatment of dental emergencies in pediatric patients. GÜ Diş Hek Fak Derg 2012;29(1):7-10.

10. Gökalp S, Doğan B, Tekcicek M, Berberoglu A, Sengul U. The oral health profile of adults and elderly, Turkey-2004. Hacettepe Dişhekimliği Fakültesi Dergisi 2007;31(4):11-18.

11. Neely M, Jones JA, Rich S, Gutierrez LS, Mehra P. Effects of cuts in Medicaid on dental-related visits and costs at a safetynet hospital. Am J Public Health 2014 Jun;104(6):e13-e16.

12. Luzzi L, Spencer AJ. Public dental service utilization among adults in South Australia. Aust Dent J 2009 Jun;54(2):154-160.

13. Cohen L, Bonito A, Akin D, Manski R, Macek M, Edwards R, Cornelius LJ. Toothache pain: a comparison of visits to physicians, emergency departments, and dentists. J Am Dent Assoc 2008 Sep;139(9):1205-1216.

14. Ma M, Lindsell CJ, Jauch EC, Pancioli AM. Effect of education and guidelines for treatment of uncomplicated dental pain on patient and provider behavior. Ann Emerg Med 2004 Oct;44(4):323-329.

15. Rodriguez D, Sarlani E. Decision making for the patient who presents with acute dental pain. AACN Clin Issues $2005 \mathrm{Jul}-$ Sep;16(3):359-372.

16. Fox TR, Li J, Stevens S, Tippie T. A performance improvement prescribing guideline reduces opioid prescriptions for emergency department dental pain patients. Ann Emerg Med 2013 Sep;62(3):237-240. 